\title{
Plant-plant interactions: from competition to facilitation
}

\author{
D. Montesinos \\ Universidade de Coimbra, Centre for Functional Ecology, Coimbra, Portugal \\ Correspondence to: D. Montesinos (daniel.montesinos@uc.pt)
}

The way plant species influence the composition of their surrounding plant community has been a subject of interest since Alexander von Humboldt developed the foundations of biogeography in the 19th century. In the same century, Adolphe Dureau de la Malle introduced a preliminary idea of succession (1825), formally developed by the end of the century by Henry Chandler Cowles (1899) and founded on the importance of environmental constraints and plantplant competitive interactions. The view of plant-plant interactions as primarily competitive was nearly exclusive until the end of the 20th century, when Bertness and Callaway formally established the concept of facilitation, as opposed to competition, to stress the importance of mutualism among plant species in shaping plant communities (Bertness and Callaway, 1994; Callaway, 1995). Those foundational papers started an important movement devoted to the study of positive interactions among plants, and Web Ecology, first published in the year 2000, has played a significant role in propagating those ideas in its pages since then; this includes a broad range of studies and authors, including several works by R. M. Callaway and many of his collaborators.

Interestingly, most of Web Ecology's papers dealing with plant-plant interactions focused on the study of facilitation, but competition naturally also found space in our pages. For instance, Rey Benayaset et al. (2007) studied different management techniques of the use of low-cost, low-impact techniques on restoration of Quercus coccifera oak forests, finding that competition had a strong impact on oak recruitment and that simple clipping of competing vegetation resulted in similar effects to those of more thorough and expensive treatments of competition removal. Other studies ( $\mathrm{Li}$ et al., 2007) did try to detect facilitation between pairs of species but found prevailing competition between two species inhabiting mobile dunes, although the presence of one species created a wind barrier that modified prevailing airstreams and strongly influenced the spatial pattern of seed dispersal of the second species. This provided further evidence of the effect of shrubs as a source of spatial heterogeneity.
Some facilitation studies made important contributions to the management and conservation of a single keystone species. Arrieta and Suárez (2001) reported the facilitative effect of nurse Ilex aquifolium (holly) shrubs and successfully related the observed spatial pattern to differences in light, dispersal, and disturbance, with important implications for holly conservation in southern Europe. Other studies had a large-scale vision and embraced the study of plant-plant interactions at landscape levels, even comparing similar habitats across continents. For instance, Marañón et al. (2009) studied the ecological factors influencing Mediterranean oak savannas occurring in either California or the Iberian Peninsula. They discussed the complex facilitative and competitive interactions that explain the coexistence of oak trees and herbaceous species in Mediterranean savannas and dehesas. Different factors acted at different spatial scales, from large-spatial-scale rainfall and water availability to local- and patch-scale factors related to disturbance, water distribution, and fire, proposing different models integrating complex facilitative and competitive interactions. Other important ecological generalizations were also established in our pages. Reid et al. (2010) performed a systematic review of the ecological literature on cushion plants, which were found to be real champions of facilitation due to the microclimatic conditions found within their compact and prostrate canopies and the particular importance of those more favorable conditions on the highly stressful environments that they inhabit, making them keystone species in the ecosystems they inhabit. Ariza and Tielbörger (2012) found that biomass explained the intensity of facilitative interactions but not of competitive ones. The assumption that increased biomass results in increased competition was challenged by intra-specific tests with three different annual herbs, for which a consistent pattern of size-dependent facilitation interactions was observed across life stages, explained as predominantly aboveground facilitation via water stress alleviation and predominant below-ground competition for water. Saiz et al. (2014) evaluated the interaction between grazing and aridity on the patch structure of gypsophila plant communities and the role 
of specialists as facilitators of other plant species. Specialist gypsophila plants were significant facilitators, but their relative importance depended on grazing and aridity.

Despite the short timespan since the formal study of facilitation was established, it has been a hot topic in the ecological literature with a considerable impact among researchers. Lortie and Callaway (2009) studied the relative abundance and quality of scientific literature dealing with competition (metaphorically described as Goliath) and facilitation (David), finding that although the long tradition of the study of competition has produced a much higher net amount of papers dealing with competition, papers dealing with facilitation received a similar mean number of citations. This very clearly illustrated the fact that quality is more important than quantity for the relevance of scientific studies - a vision that we fully embrace in Web Ecology.

\section{References}

Ariza, C. and Tielbörger, K.: Biomass explains the intensity of facilitative - not competitive - interactions: three intraspecific tests with annuals, Web Ecol., 12, 49-55, doi:10.5194/we-12-492012, 2012.

Arrieta, S. and Suárez, F.: Seedling diversity and spatially related regenaration dynamics in holly woodlands and surrounding habitats, Web Ecol., 2, 38-46, doi:10.5194/we-2-38-2001, 2001.

Bertness, M. D. and Callaway, R. M.: Positive interactions in communities, Trends Ecol. Evol., 9, 191-193, 1994.

Callaway, R. M.: Positive interactions among plants, Bot. Rev., 61, 306-349, doi:10.1007/bf02912621, 1995.
Cowles, H. C.: The Ecological Relations of the Vegetation on the Sand Dunes of Lake Michigan, The University of Chicago Press, Chicago, 1899.

De la Malle, A. D.: Mémoire sur l'alternance ou sur ce problème: la succession alternative dans la reproduction des espèces végétales vivant en société, est-elle une loi générale de la nature, Ann. des Sci. Nat., 353-381, 1825.

Li, F.-R., Li, G., Kang, L.-F., Huang, Z.-G., Wang, Q., and Liu, J.-L.: Effects of a nurse shrub on seed deposition and seedling recruitment of the annual Agriophyllum squarrosum, Web Ecol., 7, 94-105, doi:10.5194/we-7-94-2007, 2007.

Lortie, C. J. and Callaway, R. M.: David and Goliath: Comparative use of facilitation and competition studies in the plant ecology literature, Web Ecol., 9, 54-57, doi:10.5194/we-9-54-2009, 2009.

Marañón, T., Pugnaire, F. I., and Callaway, R. M.: Mediterraneanclimate oak savannas: The interplay between abiotic environment and species interactions, Web Ecol., 9, 30-43, doi:10.5194/we-930-2009, 2009.

Reid, A. M., Lamarque, L. J., and Lortie, C. J.: A systematic review of the recent ecological literature on cushion plants: champions of plant facilitation, Web Ecol., 10, 44-49, doi:10.5194/we-1044-2010, 2010.

Rey Benayas, J. M., Fernández, A., and Aubenau, A.: Clipping herbaceous vegetation improves early performance of planted seedlings of the Mediterranean shrub Quercus coccifera, Web Ecol., 7, 120-131, doi:10.5194/we-7-120-2007, 2007.

Saiz, H., Alados, C. L., and Pueyo, Y.: Plant-plant spatial association networks in gypsophilous communities: the influence of aridity and grazing and the role of gypsophytes in its structure, Web Ecol., 14, 39-49, doi:10.5194/we-14-39-2014, 2014. 